\title{
Device or Device Component Manufacturing
}

National Cancer Institute

\section{Source}

National Cancer Institute. Device or Device Component Manufacturing. NCI Thesaurus. Code C113018.

A process that involves designing, fabrication, assembly and/or processing of a device or device component. 